DOI: 10.12731/2070-7568-2021-10-2-84-98 УДК 316.48

\title{
АНАЛИЗ КОНФЛИКТНОЙ СРЕДЫ ВНУТРИ КОЛЛЕКТИВА НА ПРИМЕРЕ ПЕРСОНАЛА МЕДИЦИНСКОГО УЧЕРЕЖДЕНИЯ
}

\author{
Шакирова Д.М., Султанова Г.М., Томашова А.Г., \\ Иванова К.В., Имашева Ш.Е., Иванова Ю.А.
}

В статье раскрывается понятие конфликта с точки зрения сочиального и психологического явления, на базе теоретических материалов выявляется его наиболее распространенный тип, а также рассматривается специфика конфликта в организации и влияние на работу внутри нее. В научной работе представлен анализ конфликтов на примере выбранного медицинского учреждения. В ходе исследования была составлена анонимная анкета, включающуая в себя вопросы, отвечая на которые сотрудники организачии высказываются о наличии причин конфликтов в своем коллективе, а также дают индивидуальную оченку о рабочей среде коллектива и организации с учетом конфликтов. Результаты исследования представлены в виде статьи с количественными данными, полученныли в ходе опроса и анализа данных. Выводы, полученные в прочессе обработки результатов, способствуют выявлению предполагаемой методики разрешения конфликтов и дальнейшему решению конфликтных ситуаций в организациях подобного типа.

Цель исследования - изучить конфликтные ситуации на примере выбранного коллектива, определить их причины и способы решения.

Метод или методология проведения работы: в статье использовались статистические методы анализа, а также практическое исследование на основе анкетирования.

Результаты: получены данные о «конфликте» как социальном явлении, проанализирована конфликтная среда выбранной органи- 
зачии, сделаны выводы о причинах конфликта и предложены пути разрешения конфликтных ситуаций.

Область применения результатов: полученные результать имеют место применения как в научных и учебных цуелях для демонстрации явления конфликта и примере конфликтной среды, а так же в прочессе обучения и найма менеджеров организачий любого уровня, для четкого понимания сотрудника о конфликте.

Ключевые слова: конфликт; конфликтная среда; респондент; межличностные конфликты; рабочая среда

\section{ANALYSIS OF THE CONFLICT ENVIRONMENT WITHIN THE TEAM ON THE EXAMPLE OF THE STAFF OF THE MEDICAL INSTITUTION}

\section{Shakirova D.M., Sultanova G.M., Tomashov A.G., Ivanov K.V., Imashev S.E., Ivanova Y.A.}

The article reveals the concept of conflict in terms of social and psychological phenomena, on the basis of theoretical material is revealed its most common type, and deals with the specifics of the conflict in the organization and the impact on the work within it. The research paper presents an analysis of conflicts on the example of the selected medical institution. During the study, an anonymous questionnaire was compiled, which includes questions, answering which the employees of the organization express about the presence of the causes of conflict in their team, as well as give an individual assessment of the working environment of the team and the organization, taking into account the conflicts. The results of the study are presented in the form of an article with quantitative data from the survey and data analysis. The conclusions obtained during the processing of the results contribute to the identification of the intended methodology of conflict resolution and further resolution of conflict situations in organizations of this type.

Purpose of the study - to study conflict situations on the example of the selected team, to determine their causes and ways of solving. 
Method or methodology of work: the article used statistical methods of analysis, as well as practical research based on the questionnaire.

Results: data on the "conflict" as a social phenomenon was obtained, the conflict environment of the selected organization was analyzed, conclusions were drawn about the causes of conflict and ways to resolve conflict situations were proposed.

Scope of the results: the obtained results have a place of application as in scientific and educational purposes to demonstrate the phenomenon of conflict and the example of the conflict environment, as well as in the process of training and hiring managers of organizations of any level, for a clear understanding of the employee about the conflict.

Keywords: conflict; conflict environment; respondent; interpersonal conflicts; work environment

\section{Введение}

По определению Джон фон Неймана и О. Моргенштерна [8] конфликт - это взаимодействие двух объектов, обладающих несовместимыми целями и способами достижения этих целей.

Разные системы ценностей, недопонимания и разногласия между людьми - естественные социальные явления, оправданные противоречивой природой человека.[2] Конфликт как феномен изучается социологами, психологами, юристами, но несмотря на активную заинтересованность научного сообщества данным явлением, до сих пор нет единого, однозначного и всеми признанного определения социального конфликта. С каждым годом исследования, предметами которых являются человеческие взаимоотношения, становятся все более актуальными. Это обусловлено резким скачком технологического прогресса, который отодвигает на второй план значимость человеческого фактора и его отражение на эффективности любой работы.

Проведенный анализ межличностного конфликта на основе персонала медицинского учреждения раскрывает сущность конфликта в организации, а также его влияние на атмосферу внутри коллектива.

Новизна работы заключается в тщательном анализе конфликтов, их сравнении и выявлении закономерностей. 
Цель работы - Изучить межличностный конфликт как отдельный типа конфликта на примере персонала медицинского учреждения.

\section{Материалы и методы исследования}

Теоретической основой выступили работы отечественных и зарубежных исследований конфликта как явления. Прикладная часть работы основана на использовании такого метода как опрос.

\section{Результаты исследования и их обсуждение}

Согласно психологу Курту Левину [5] «конфликт» - ситуация, в которой на индивида одновременно действуют противоположно направленные силы примерно равной величины. Наряду с «силовыми» линиями ситуации активную роль в разрешении конфликтов, их понимании и видении играет сама личность [4].

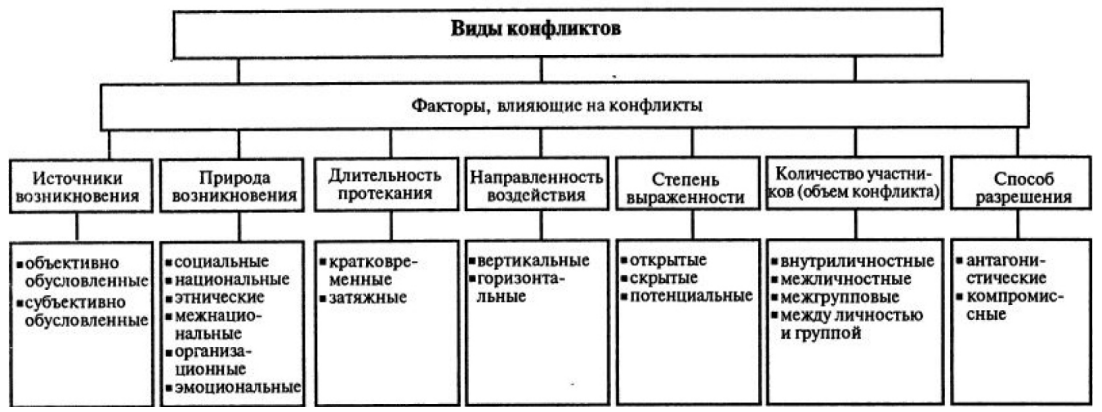

Рис. 1. Классификация конфликтов в зависимости от факторов [16]

Поэтому в работах Левина рассматриваются как внутриличностные, так и межличностные конфликты (рисунок 1). В рамках исследования достаточно рассмотреть особенности, виды и классификации столкновений исключительно межличностного характера. Более подробное определение термину «межличностный конфликт» даёт профессор Н.В. Гришина [3]. Она считает, что межличностный конфликт представляет собой ситуацию противостояния участников, воспринимаемого и переживаемого ими (или по крайней мере, одним из них) как значимая психологическая проблема [9], требующая 
своего разрешения и вызывающая активность сторон, направленную на преодоление возникшего противоречия и разрешение ситуации в интересах обеих или одной из сторон.

Общепринятые стандарты рассматриваемой области предоставляют нам следующую классификацию межличностных конфликтов [3]:

- мотивационный (конфликт интересов);

- н нравственный;

- когнитивный (ценностный);

- нереализованного желания;

- ролевой (скрытный и открытый);

- адаптационный;

- неадекватной самооценки.

В практической части исследования мы исходили из того, что любой межличностный конфликт это противостояние интересов. У каждого члена рабочего коллектива степень мотивации и уровень заинтересованности в успехе работы команды всегда будут разные. Не смотря на то, что цель существования организаций чётко обозначается, цели пребывания в этой организации каждого из сотрудников могут быть различными. Говоря о человеческих деловых отношениях, нельзя оставлять без внимания и такое понятие, как «конкуренция», которое является ключевым при изучении межличностных противостояний в рабочей среде. Заинтересованность сотрудников в эффективной командной работе, мотивированность каждого из членов коллектива, а также уровень профессиональной компетенции сотрудников помогут составить общую картину конфликтности рабочей среды.

Исследуемой рабочей средой стало частное медицинское учреждение Республики Татарстан, расположенное в городе Казань. Изучаемая организация занимается диагностикой и лечением сердечно сосудистых заболеваний и заболеваний нервной системы. Общая численность рабочего штаба, включая административных работников, составляет 138 человек, 76 из которых ответили на вопросы анкетирования. Респондентами стали врачи-кардиологи, неврологи, заведующие отделениями, лаборанты и функциональные диагносты. 
Согласно полученным результатам социально-психологический климат организации можно считать скорее положительным, так как 67 респондентов, что составляет $88 \%$ (рисунок 2) от общего числа опрашиваемых, считают конфликты не значимой проблемой и оценивают их влияние на работу коллектива, как «низкое». Также это связано с ответом аналогичного количества сотрудников на вопрос о частоте возникновения противоречивых ситуаций - выбранный вариант ответа «редко».

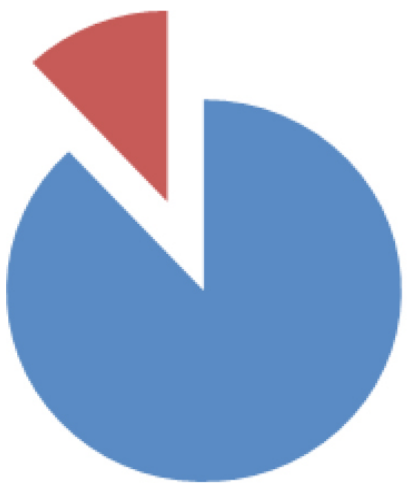

\section{Низкое} Высокое

Рис. 2. Влияние конфликтов на работу коллектива

Малую долю составляют работники, которые недовольны работой коллектива и испытывают негативные эмоции при выполнении своих прямых обязанностей (рисунок 3). Говоря точнее, такой ответ дали 5 сотрудников, что соответствует 7\% от числа всех респондентов. Вполне логично, что именно столько же работников выразили недовольство большинством решений, которые принимаются вышестоящим начальством. Исходя из этих данных, можно заключить, что основным источником конфликтных ситуаций является фактор недопонимания между рядовыми сотрудниками и руководством.

Подавляющее большинство, а именно $84 \%$ опрошенных сотрудников, заинтересовано в разрешение спорных моментов. Наиболее популярным ответом на вопрос о предпочитаемых методах решения конфликтов стал метод «компромисс». Анкетируемые считают, что активная позиция их руководителя и уровень вовлечённости в рабо- 
ту рядовых сотрудников позволяют обсуждать насущные вопросы на организационных собраниях и решать их путём поиска самого гуманного и логичного исхода для обеих сторон любого конфликта. Более того, на вопрос: «Какие исходы конфликта представляются наиболее приемлемыми для Вас?» 74 из 76 работников ответили, выбрав пункт «поиск взаимовыгодных вариантов», что говорит о высокой профессиональной компетентности сотрудников.

Вы недовольны работой коллектива и испытываете негативные эмочии при выполнении своих прямых обязанностей

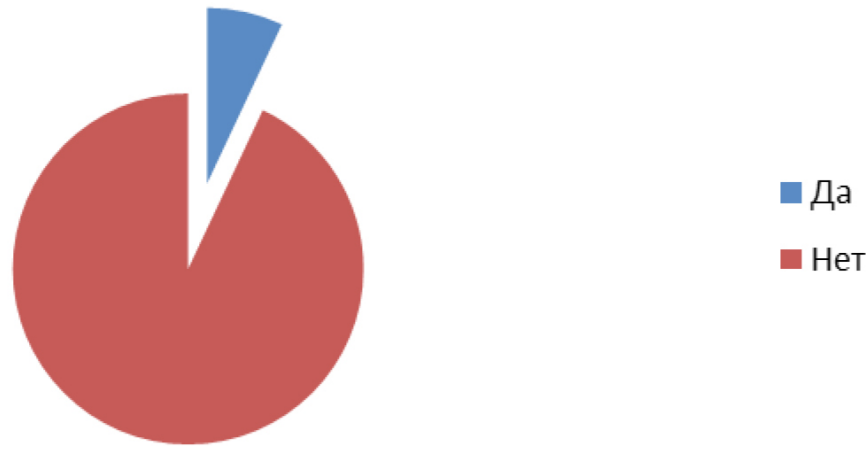

Pис. 3.

Небольшое число респондентов предпочитают принимать нейтральную сторону в любом спорном моменте, такая пассивная позиция тормозит развитие в коллективе, что негативно отражается на работе организации. Объясняется это тем, что равнодушие по отношению к насущным вопросам рабочего процесса говорит о низком уровне заинтересованности и мотивированности некоторых работников. Уменьшение их числа поможет снизить уровень конфликтности в рассматриваемом медицинском учреждении.

Для мотивации своих подчинённых руководитель данной организации выбирает разные методы, всё больше отдавая предпочтение современным способам разрешения конфликтов, таких, как «анонимное заполнение гугл формы о волнующих вопросах», при- 
глашение психологов-конфликтологов на открытые беседы с сотрудниками, систематическое проведение не рабочих мероприятий для сплочения коллектива. Начальник организации предпочитает демократический стиль управления в организации труда своего коллектива, что одобряют все $100 \%$ респондентов, считая данный стиль самым прогрессивным и наиболее применимым именно к медицинским учреждениям, где умение «слышать и слушать» превыше всего. Работа таких коллективов требует большой стрессоустойчивости, так как конфликты и недопонимания внутри коллектива могут негативно сказаться на работе сотрудников, основная деятельность которых направлена на помощь заболевающим людям, что уже предполагает колоссальную энергозатратность и повышенную ответственность при работе.

Также в анкету был включён вопрос о причинах возникновения противоречивых ситуаций, в котором предлагалось перечислить самые частые из них. По итогам опроса возглавляют этот список «неравномерное распределение рабочей нагрузки», «необоснованное поощрение и выдача премиальных», а также «человеческий фактор: эмоциональная несдержанность некоторых коллег».

Результаты анкетирования показали, что для работников изучаемого коллектива важна обоснованность решений, принимаемых руководством. На это указывают 89\% (67 чел.) опрошенных, которые считают «несправедливость» главной проблемой организации.

В ходе обработки результатов выявлена разобщенность коллектива в изучаемых вопросах, из чего следует необходимость в сплочении коллектива, развитии корпоративного духа и разработки мер, применимых для организаций с аналогичной профессиональной направленностью.

\section{Заключение}

Для конкретизации необходимых мер были изучены материалы работ, изучающих все частные стороны социально-психологического климата в медицинских организациях. На основе сопоставления данных анкетирования с материалами вышеуказанных работ, можно 
предложить пути решения конфликтных ситуаций в организациях со схожими проблемами.

1. Необходимо учитывать психологическую совместимость работников при формировании коллектива. Сочетания различных типов людей, исходя из их целей, поможет скомплектовать коллектив с едиными задачами и руководителем, направленным на конкретную область.

2. Морально-психологическое стимулирование коллектива. В ходе анкетирования была выявлена низкая заинтересованность коллектива в конфликтных ситуациях и поверхностное отношение к их решению. Руководителю следует установить конкретные и единые понятия о конфликтных ситуациях в коллективе и на фоне реакции коллектива на единую проблему разрабатывать пути индивидуальных морально-психологических стимулов.

3. Ввести индивидуальные и коллективные собрания с руководителем для обработки вопросов и недовольств сотрудников. Не смотря на малое количество сотрудников с отрицательным восприятием указов руководителя и недовольствами работой, меньшинство может так же оказывать влияние на остальную часть коллектива. Следует ввести беседы, собрания для разбора всех возникающих проблем и устранению негативного восприятия руководителя и коллектива.

Так же согласно изученной теории, самым оптимальным выходом из данной ситуации является введение наглядной бально-рейтинговой системы, которая уже используется в работе многих коллективов[10]. Основной целью предложенной системы является определение уровня качества и успешности оказания помощи клиентам учреждения. Рейтинговая форма контроля работы исключит человеческий фактор, она поможет отследить логичность премирования сотрудников и оправдает решение руководства о повышении того или иного сотрудника. Такой рейтинг помог бы объективно оценивать работу каждого члена организации, беря во внимание все его достижения и своевременное выполнение плана. К тому же такая объективная система оценивания поможет нормализовать ситуацию с конкуренцией, сделав ее здоровой, и, послужит дополнительной мотивацией для сотрудников. 
Следует отметить, что все вышеперечисленные рекомендации применимы и для других медицинских коллективов, так как структура и принцип работы таких организаций схожи.

В силу противоречивой природы человека, конфликты всегда будут оставаться значимой проблемой любого рабочего коллектива. Изучая и анализируя причины спорных моментов, можно минимизировать внутренние конфликтные ситуации, которые явно отражаются на эффективности рабочего процесса.

Межличностные конфликты проявляются во всех сферах жизни и поддаются управлению, которое сводится к изучению причин и факторов, воздействия на сферу конфликтных взаимоотношений, выбор стратегии и способы поведения. Необходимо понимать, что степень масштабности конфликтов будет зависеть от осознания данной проблемы и вовлеченности всего коллектива в борьбу с ней.

\section{Список литературы}

1. Афанасьева Е. Практика решения межличностных конфликтов в организациях // Устойчивость бизнеса. 2019. https:/constanta.co/blog/ praktika-resheniya-mezhlichnostnykh-konfliktov-v-organizatsiyakh

2. Водолазова Е. Конфликтность и его управление в организации. Мнение экспертов по кадровой политике // Бухгалтерский учет. Налоги. Аудит. 2018. https://www.audit-it.ru/articles/personnel/a114/950789.html

3. Гришина Н.В. Психология конфликта. СПб.: Питер, 2008. 544 с.

4. Живага А.Ю. Управление конфликтами и стрессами в организации: учебное пособие. Южно-Сахалинск : СахГУ, 2019. 108 с.

5. Левин К. Динамическая психология: Избранные труды. М.: Смысл, 2001. С. 3-20.

6. Легатова В.В. Совершенствование системы профилактики межличностных конфликтов в организации // Образование и наука в России и за рубежом. 2020. Т. 66, №2. https://www.gyrnal.ru/statyi/ru/1971/

7. Митина О.В., Перпер А.М., Абдуллаева Л.Ш. Исследование взаимосвязи личностных характеристик и динамики эмоциональной сферы в ситуации длительного стресса // Психологические исследования. 2019. Т. 12, № 63. http://psystudy.ru/index.php/num/2019v12n63/1673-mitina63.html 
8. Моргенштерн О. Теория игр и экономическое поведение / О. Моргенштерн, Дж. фон Нейман. М.: Книга по Требованию, 2012. 708 с.

9. Слободян Л.Д. Межличностные конфликты в системе управления // Современные общество и власть. 2018. http:/gmanagement.ru/index. php/ru/arxiv/172018/775-slobodianld-172018

10.Хрулева Е.Н. Межличностные конфликты и пути их преодоления // Материалы Ивановских чтений. 2018.

11. Yin J., Jia M., Ma Z. Liao G. Team leader's conflict management styles and innovation performance in entrepreneurial teams // International Journal of Conflict Management, 2020, vol. 31, no. 3, pp. 373-392. DOI: https://doi.org/10.1108/IJCMA-09-2019-0168

12. Hjerto K.B., Kuvaas B. Burning hearts in conflict: New perspectives on the intragroup conflict and team effectiveness relationship // International Journal of Conflict Management, 2017, vol. 28, no. 1, pp. 50-73. DOI: https://doi.org/10.1108/IJCMA-02-2016-0009

13. Laura K. Guerrero. Conflict Style Associations with Cooperativeness, Directness, and Relational Satisfaction: A Case for a Six-Style Typology // Negotiation and Conflict Management Research, 2019, vol. 13, no. 1, pp. 24-43. DOI: https://doi.org/10.1111/ncmr.12156

14. Kevin J. Hurt, Jennifer Welbourne. Conflict and Decision-Making: Attributional and Emotional Influences // Negotiation and Conflict Management Research, 2018, vol. 11, no. 3, pp. 225-251. DOI: https://doi. org/10.1111/ncmr.12133

15. Miriam S. D. Oostinga, Sonja Rispens, Paul J. Taylor, Elze G. Ufkes. HighStakes Conflicts and the Link between Theory and Practice: Celebrating the Work of Ellen Giebels // Negotiation and Conflict Management Research, 2018, vol. 11, no. 2, pp. 146-159. DOI: https://doi.org/10.1111/ncmr.12123 16.https://psyera.ru/4549/klassifikaciya-i-funkcii-konfliktov

\section{Referensces}

1. Afanas'eva E. Praktika resheniya mezhlichnostnykh konfliktov v organizatsiyakh [Practice of resolving interpersonal conflicts in organizations]. Ustoychivost' biznesa [Business stability]. 2019. https://constanta.co/ blog/praktika-resheniya-mezhlichnostnykh-konfliktov-v-organizatsiyakh 
2. Vodolazova E. Konfliktnost' i ego upravlenie v organizatsii. Mnenie ekspertov po kadrovoy politike [Conflict and its management in the organization. The opinion of experts on personnel policy]. Bukhgalterskiy uchet. Nalogi. Audit [Accounting. Taxes. Audit]. 2018. https://www.audit-it.ru/articles/personnel/a114/950789.html

3. Grishina N.V. Psikhologiya konflikta [The psychology of conflict]. SPb.: Piter, 2008, 544 p.

4. Zhivaga A.Yu. Upravlenie konfliktami i stressami v organizatsii [Managing conflicts and stress in the organization]. Yuzhno-Sakhalinsk: SakhGU, 2019,108 p.

5. Levin K. Dinamicheskaya psikhologiya: Izbrannye trudy [Dynamic psychology: Selected works]. M.: Smysl, 2001, pp. 3-20.

6. Legatova V.V. Sovershenstvovanie sistemy profilaktiki mezhlichnostnykh konfliktov v organizatsii [Improving the system of prevention of interpersonal conflicts in the organization]. Obrazovanie $i$ nauka $v$ Rossii $i$ za rubezhom, 2020, vol. 66, no. 2. https://www.gyrnal.ru/statyi/ru/1971/

7. Mitina O.V., Perper A.M., Abdullaeva L.Sh. Issledovanie vzaimosvyazi lichnostnykh kharakteristik i dinamiki emotsional'noy sfery v situatsii dlitel'nogo stressa [Investigation of the relationship between personal characteristics and the dynamics of the emotional sphere in a situation of prolonged stress]. Psikhologicheskie issledovaniya, 2019, vol. 12, no. 63. http://psystudy.ru/index.php/num/2019v12n63/1673-mitina63.html

8. Morgenshtern O., Dzh. fon Neyman. Teoriya igr i ekonomicheskoe povedenie [Game theory and economic behavior]. M.: Kniga po Trebovaniyu, 2012, 708 p.

9. Slobodyan L.D. Mezhlichnostnye konflikty v sisteme upravleniya [Interpersonal conflicts in the management system]. Sovremennye obshchestvo $i$ vlast', 2018. http://gmanagement.ru/index.php/ru/arxiv/172018/775-slobodianld-172018

10. Khruleva E.N. Mezhlichnostnye konflikty i puti ikh preodoleniya [nterpersonal conflicts and ways to overcome them]. Materialy Ivanovskikh chteniy [Materials of Ivanovskiye readings]. 2018.

11. Yin J., Jia M., Ma Z. Liao G. Team leader's conflict management styles and innovation performance in entrepreneurial teams. International Jour- 
nal of Conflict Management, 2020, vol. 31, no. 3, pp. 373-392. DOI: https://doi.org/10.1108/IJCMA-09-2019-0168

12. Hjerto K.B., Kuvaas B. Burning hearts in conflict: New perspectives on the intragroup conflict and team effectiveness relationship. International Journal of Conflict Management, 2017, vol. 28, no. 1, pp. 50-73. DOI: https://doi.org/10.1108/IJCMA-02-2016-0009

13. Laura K. Guerrero. Conflict Style Associations with Cooperativeness, Directness, and Relational Satisfaction: A Case for a Six-Style Typology. Negotiation and Conflict Management Research, 2019, vol. 13, no. 1, pp. 24-43. DOI: https://doi.org/10.1111/ncmr.12156

14. Kevin J. Hurt, Jennifer Welbourne. Conflict and Decision-Making: Attributional and Emotional Influences. Negotiation and Conflict Management Research, 2018, vol. 11, no. 3, pp. 225-251. DOI: https://doi. org/10.1111/ncmr.12133

15. Miriam S. D. Oostinga, Sonja Rispens, Paul J. Taylor, Elze G. Ufkes. High-Stakes Conflicts and the Link between Theory and Practice: Celebrating the Work of Ellen Giebels. Negotiation and Conflict Management Research, 2018, vol. 11, no. 2, pp. 146-159. DOI: https://doi.org/10.1111/ ncmr. 12123

16.https://psyera.ru/4549/klassifikaciya-i-funkcii-konfliktov

\section{ДАННЫЕ ОБ АВТОРЕ}

Шакирова Динара Марселевна, доцент кафедры «Менеджмент», кандидат социологических наук.

Казанский государственный энергетический университет ул. Красносельская, 51, г. Казань, Республика Татарстан, 420066, Российская Федерация

dinara.mm@yandex.ru

Султанова Гулия Мирзаевна, студент кафедры «Экономика и организация производства»

Казанский государственный энергетический университет ул. Красносельская, 51, г. Казань, Республика Татарстан, 420066, Российская Федеращия guliya_sultanova@inbox.ru 
Томашова Анастасия Георгевна, студент кафедры «Промышленная теплоэнергетика»

Казанский государственный энергетический университет ул. Красносельская, 51, г. Казань, Республика Татарстан, 420066, Российская Федеращия n-tomashova@mail.ru

Иванова Карина Владимировна, студент кафедры «Экономика и организация производства»

Казанский государственный энергетический университет ул. Красносельская, 51, г. Казань, Республика Татарстан, 420066, Российская Федеращия Kari29082001@mail.ru

Имашева Шолпан Еркиновна, студент кафедры «Промышленная теплоэнергетика» Казанский государственный энергетический университет ул. Красносельская, 51, г. Казань, Республика Татарстан, 420066, Российская Федерачиия isholpan2001@list.ru

Иванова Юлия Александровна, студент кафедры «Экономика и организация производства» Казанский государственный энергетический университет ул. Красносельская, 51, г. Казань, Республика Татарстан, 420066, Российская Федерация ivanova_yulia.01@mail.ru

\section{DATA ABOUT THE AUTHORS}

Shakirova Dinara M., Associate Professor of Management, Candidate of Sociological Sciences.

Kazan State Energy University

51, Krasnoselskaya Str., Kazan, Republic of Tatarstan, 420066, Russian Federation dinara.mm@yandex.ru 
Sultanova Gulia M., Student of the Department "Economics and Organization of Production"

Kazan State Energy University

51, Krasnoselskaya Str., Kazan, Republic of Tatarstan, 420066, Russian Federation

guliya_sultanova@inbox.ru

Tomashova Anastasia G., Student of the Department of Industrial Thermal Power Engineering Kazan State Energy University

51, Krasnoselskaya Str., Kazan, Republic of Tatarstan, 420066, Russian Federation

n-tomashova@mail.ru

Ivanova Karina V., Student of the Department "Economics and Organization of Production"

Kazan State Energy University

51, Krasnoselskaya Str., Kazan, Republic of Tatarstan, 420066, Russian Federation

Kari29082001@mail.ru

Imasheva Sholpan E., Student of the DEPARTMENT of Industrial Thermal Power Engineering Kazan State Energy University

51, Krasnoselskaya Str., Kazan, Republic of Tatarstan, 420066, Russian Federation isholpan2001@list.ru

Ivanova Yulia A., Student of the Department "Economics and Organization of Production"

Kazan State Energy University

51, Krasnoselskaya Str., Kazan, Republic of Tatarstan, 420066, Russian Federation ivanova_yulia.01@mail.ru 